Technological University Dublin

DÜBLIN

ARROW@TU Dublin

2006-01-01

\title{
Compact Annular-ring Embedded Circular Patch Antenna with Cross-slot Ground Plane for Circular Polarisation
}

Xiulong Bao

Technological University Dublin, xiulong.bao@tudublin.ie

Max Ammann

Technological University Dublin, max.ammann@tudublin.ie

Follow this and additional works at: https://arrow.tudublin.ie/engscheceart

Part of the Electrical and Computer Engineering Commons

\section{Recommended Citation}

Bao, X., Ammann, M.: Compact annular-ring embedded circular patch antenna with cross-slot ground plane for circular polarisation. Electronics Letters, 16 Feb, 2006, Vol. 42, pp. 192-13, doi:10.1049/ el:20064199

This Article is brought to you for free and open access by the School of Electrical and Electronic Engineering at ARROW@TU Dublin. It has been accepted for inclusion in Articles by an authorized administrator of ARROW@TU Dublin. For more information, please contact arrow.admin@tudublin.ie, aisling.coyne@tudublin.ie, gerard.connolly@tudublin.ie.

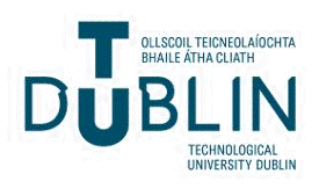




\section{Compact annular-ring embedded circular patch antenna with cross-slot ground plane for circular polarisation}

\section{X.L. Bao and M.J. Ammann}

A compact circular patch antenna embedded in a narrow annular-ring which uses an unequal cross-slotted ground plane is presented. This new compact structure provides circular polarisation and is easily matched to $50 \Omega$ at the low frequency of operation. The size of the proposed antenna is reduced by over $55 \%$ compared to the conventional annular-ring CP patch antenna with a strip. The bandwidth and centre-frequency show weak dependence on the position of the feedpoint in the patch and demonstrate wider manufacturing tolerances. Good circularly polarised properties and wide bandwidth are obtained for the proposed compact antenna.

Introduction: Antenna miniaturisation plays a vital role in the design of global positioning systems and modern personal wireless systems. Many techniques have been reported to reduce the patch antenna size, such as a square-ring patch fed by a microstrip line, the use of cross and bent slots embedded in the radiating patch [1-3] and the use of a slot in the ground plane [4]. The purpose of these methods is to lengthen the excited surface current path, increasing the antenna length and decreasing the resonant frequency.

Recently, an annular-ring patch antenna with strips has been used to obtain circular polarisation characteristics $[5,6]$. For a patch embedded in a wide annular-ring, the feedpoint for $50 \Omega$ input impedance is very easily found. But in the case of a narrow annular-ring patch, which has a lower resonant frequency, a high input impedance is seen. It proves very difficult to obtain a $50 \Omega$ match.

In this Letter, a circular patch embedded into a narrow annular-ring which employs a cross slot in the ground plane is used to decrease the resonant frequency and obtain a lower frequency of operation. At the same time, respectable bandwidths of impedance and axial-ratio are seen and good radiation patterns are demonstrated. This new annular-ring embedded patch also provides convenient matching to $50 \Omega$. Results show that this antenna has a significantly lower resonant frequency than the wide annular-ring patch antenna with a strip. The simulated and measured results of the proposed antennas are shown below.

Antenna design: Fig. 1 shows the geometry of the proposed compact circularly polarised antenna. A circular patch of radius $R 3$ is centred in the narrow annular-ring, of outer radius $R 1$ and inner radius $R 2$. These patches are printed on FR 4 substrate, of permittivity $\varepsilon=4.0$ and thickness $1.52 \mathrm{~mm}$. The crossed slot in the ground plane has unequal lateral lengths, $L 1$ and $L 2$, with a slot width $w$. This structure can excite two degenerate orthogonal modes with equal amplitude and $90^{\circ}$ phase difference by tuning various parameters $(R 2, R 3, L 1, L 2)$ and righthand circular polarisation (RHCP) radiation is obtained. The optimised dimensions selected are: $R 1=24.8 \mathrm{~mm}, R 2=22 \mathrm{~mm}, R 3=9.0 \mathrm{~mm}$, $L 1=48 \mathrm{~mm}, L 2=50 \mathrm{~mm}, w=2 \mathrm{~mm}$, ground plane $=100 \times 100 \mathrm{~mm}$. For better matching of input impedance, a circular slot of radius $R 4=4 \mathrm{~mm}$ is located at the centre of the cross slot. This antenna is excited by a $50 \Omega$ coaxial probe, and the position of the feedpoint along the diagonal line is located in the rectangular co-ordinates $(-5,5 \mathrm{~mm})$, where the origin is at the centre of the circular patch.
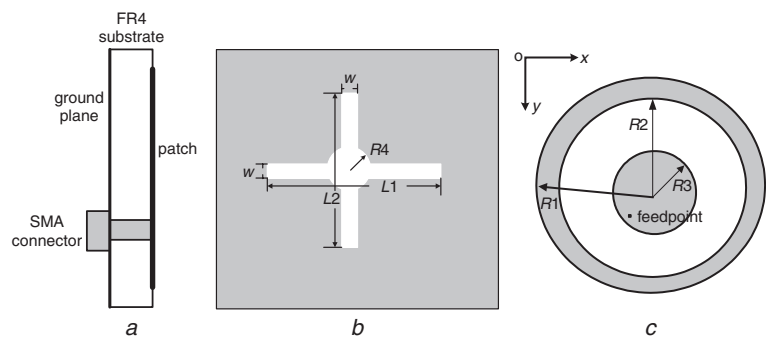

Fig. 1 Geometry of proposed circularly polarised antenna

$a$ Profile

$b$ With cross-slot ground plane

$c$ Patch on top

Simulated and measured results: The annular-ring antenna with a strip is designed as a reference antenna [6]. Fig. 2 illustrates the simulated return loss for a conventional circular patch antenna of radius $24.8 \mathrm{~mm}$ and the annular-ring CP patch antenna with a strip (same outer radius) and the measured and simulated return loss for the proposed antenna. For the same outer circle radius, using optimised inner radius $R 2=6.5 \mathrm{~mm}$ and the position of the feedpoint close to inner circle, the centre frequency of the reference antenna is $1.655 \mathrm{GHz}$, but the centre frequency of the proposed antenna is $1.070 \mathrm{GHz}$. The proposed antenna is reduced in size by over $55 \%$ and the impedance bandwidth and centre frequency of the proposed antenna is quite insensitive to the position of the feedpoint along the diagonal. The variation of return loss for different feedpoint locations is shown in Fig. 3. The measured $10 \mathrm{~dB}$ return loss impedance bandwidth is approximately $65 \mathrm{MHz}(6.1 \%)$ from 1.039 to $1.094 \mathrm{GHz}$. The simulated and measured axial-ratio (AR) is shown in Fig. 4. The measured axial-ratio bandwidth, determined for $\mathrm{AR}<3 \mathrm{~dB}$, is about $16 \mathrm{MHz}(1.6 \%)$ from 1.065 to $1.081 \mathrm{GHz}$. Spinning dipole radiation patterns measured at 1.070 GHz are shown in Fig. 5. The maximum gain was found to be $2.5 \mathrm{dBi}$.

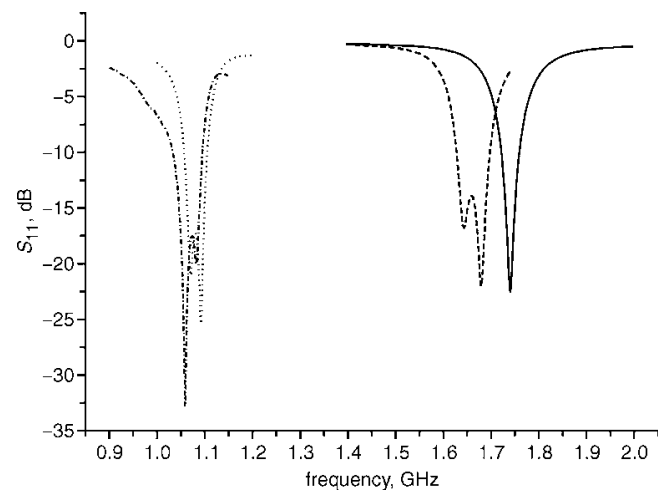

Fig. 2 Comparison of return loss for several circular patch geometries

simulated $S_{11}$ for conventional circular patch antenna

simulated $S_{11}$ for annular-ring patch antenna with strip

. . . - simulated $S_{11}$ for proposed antenna

- . - . - measured $S_{11}$ for proposed antenna

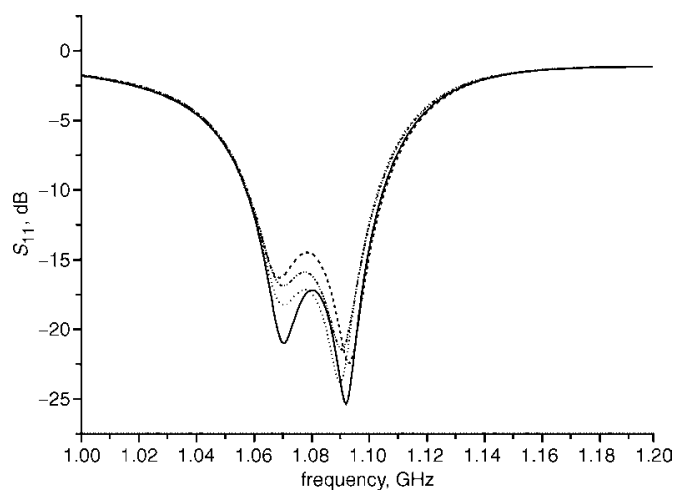

Fig. 3 Return loss insensitivity to feed position for proposed antenna

position of feedpoint $(-4.3,4.3 \mathrm{~mm})$

........ position of feedpoint $(-4.7,4.7 \mathrm{~mm})$

-

..... position of feedpoint $(-5.9,5.9 \mathrm{~mm})$

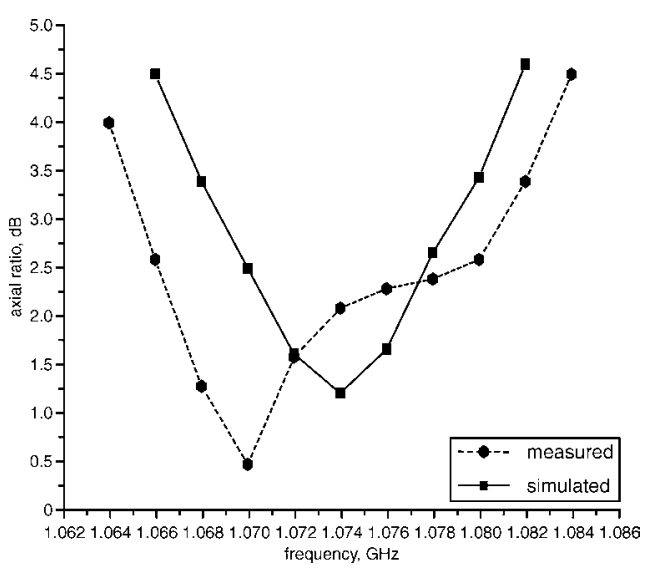

Fig. 4 Measured and simulated axial-ratio for proposed antenna 


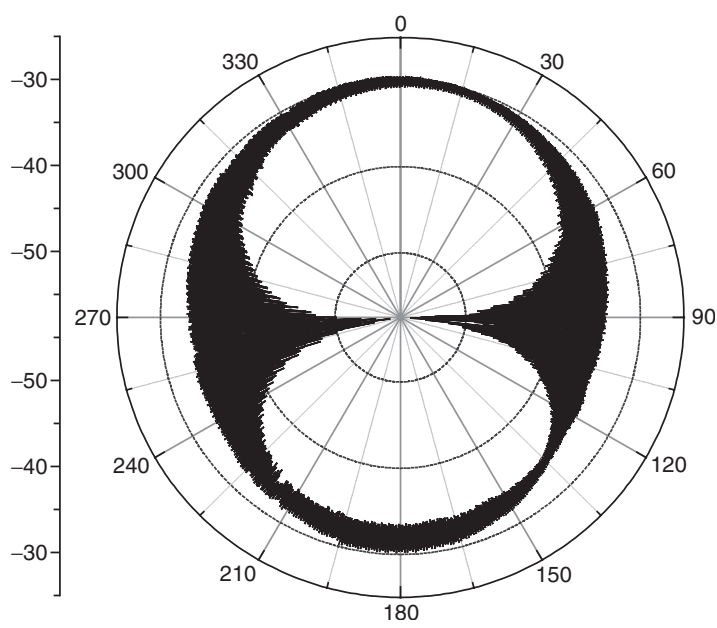

Fig. 5 Measured spinning-dipole radiation patterns at $1.070 \mathrm{GHz}$

Conclusions: A novel compact annular-ring embedded circular patch antenna employing a cross-slot ground plane is proposed. The antenna provides circular polarisation and is significantly smaller than the conventional annular-ring patch antennas with a strip. The relatively wide bandwidth and centre-frequency are not heavily dependent on the feedpoint position and the antenna provides a convenient match to $50 \Omega$, is easy to fabricate and demonstrates wide manufacturing tolerances.
(C) IEE 2006

Electronics Letters online no: 20064199 doi: 10.1049/el:20064199

X.L. Bao and M.J. Ammann (Centre for Telecommunications Valuechain Driven Research, School of Electronic \& Communications Engineering, Dublin Institute of Technology, Kevin Street, Dublin 8 , Ireland)

E-mail: max.amman@dit.ie

\section{References}

1 Huang, C.Y., Wu, J.Y., and Wong, K.L.: 'Cross-slot-coupled microstrip antenna and dielectric resonator antenna for circular polarization', IEEE Trans. Antennas Propag., 1999, 47, (4), pp. 605-609

2 Iwasaki, H.: 'A circularly polarized small-size microstrip antenna with a cross slot', IEEE Trans. Antennas Propag., 1996, 44, (10), pp. 1399 1401

3 Chen, W.S., Wu, C.K., and Wong, K.L.: 'Compact circularly polarised microstrip antenna with bent slots', Electron. Lett., 1998, 34, (13), pp. 1278-1279

4 Row, J.S., and Ai, C.Y.: 'Compact design of single-feed circularly polarised microstrip antenna', Electron. Lett., 2004, 40, (18), pp. $1093-$ 1094

5 Row, J.S., and Lin, K.W.: 'Design of an annular-ring microstrip antenna for circular polarisation', Microw. Opt. Technol. Lett., 2004, 42, (2), pp. $156-157$

6 Tamakuma, K., and Iwasaki, H.: 'A small size circularly polarized annular microstrip antenna'. IEEE AP-S Symp., 2003, Vol. 3, pp. 716-719 